\title{
Prognostic Significance of Surgical Margin, Ki-67 and Cyclin D1 Protein Expression in Grade II Canine Cutaneous Mast Cell Tumor
}

\author{
Kiyokazu OZAKI ${ }^{1) *}$, Tetsushi YAMAGAMI'), ${\text { Koji } \text { NOMURA }^{2)} \text { and Isao NARAMA }}^{1)}$ \\ ${ }^{1)}$ Department of Pathology, Faculty of Pharmaceutical Science, Setsunan University, 45-1 Nagaotohge-cho, Hirakata, Osaka 573-0101, \\ and ${ }^{2)}$ Marupi Lifetech Co., Ltd., 103 Fushio-cho, Ikeda, Osaka 563-8691, Japan
}

(Received 7 May 2007/Accepted 10 July 2007) ABSTRACT. The prognosis for canine cutaneous mast cell tumor (CCMT) is thought to be correlated with histopathological grading. How-
ever, the wide variety of histopathologic types of grade II is one of the most troublesome and difficult points for prognosis. The objective
of this study is to determine the prognostic value of surgical margin, ki-67 and cyclin D1 protein expression in grade II tumor. Surgically
resected specimens of solitary grade II CCMT from 48 dogs with follow-up periods over 360 days (median was 1080 days) were used
in this study. The expression of cyclin D1 and ki- 67 proteins was determined by morphometrically using slides stained immunocy-
tochemically, and the correlations among the results, survival rate, and recurrence and/or metastasis rate of each dog were analyzed sta-
tistically. The recurrence and/or metastasis and mortality rate in the incomplete surgical excision group within 30 months postoperatively
were higher than that of the complete surgical excision group. In the incomplete surgical excision group, dogs with low positive staining
of ki-67 had a significantly better survival, but the recurrence and metastasis rate and ki-67 positivity failed to show a significant corre-
lation. Only a small number of cases showed cyclin D1-positive tumor cells, but most of them had a poor outcome with a high recurrence
rate. In grade II CCMT, incomplete excision induced a relatively high metastasis rate and poor prognosis. Ki- 67 positivity is a marker
for the estimation of overall survival in incomplete surgical excision cases. Cyclin D1 positivity was low and may not have a prognostic
role.
KEY wORDS: canine, cyclin D1, ki-67, mast cell tumor, skin.

Cutaneous mast cell tumors (CCMT) are the most common round cell neoplasm in dogs, accounting for 7 to $21 \%$ of all skin tumors $[12,16]$. The clinical course of each dog with CCMT varied from benign to highly malignant. Various prognostic factors have been studied, including clinical stage, surgical resection [13, 21, 27], kinetic parameters (Ki67 [1, 19], BrDU [19], PCNA [23], AgNOR [11]), DNA ploidy [2], intratumoral vessel density[18], p53 [7, 8], KIT $[9,25,26]$, nuclear morphometry [24], tumor depth [10] and location [4].

The most accurate and commonly used prognostic factor is histological grade. Among the histological grading systems, Patnaik's method has been the most commonly used around the world $[3,17]$, and the prognostic significance of this method was confirmed in other studies [1, 7, 8, 23]. According to Patnaik's system, CCMT is classified into 3 categories on the basis of morphologic grading: grade I tumors are the most differentiated and have a good prognosis, grade III tumors are poorly differentiated with a poor prognosis, and grade II shows an intermediate differentiation with good to poor prognosis. Using this grading system, the prognosis of grade I and III tumors can be readily determined well [17]. However, other parameters have been needed for precise prognosis of grade II tumors, which have shown an inconsistent prognosis, the marked degree of inter-observer variation and accounted for $40 \%$ or $59 \%$ of

\footnotetext{
* Correspondence to: Ozaki, K., Department of Pathology, Faculty of Pharmaceutical Science, Setsunan University, 45-1 Nagaotohge-cho, Hirakata, Osaka 573-0101, Japan. e-mail: ozaki@pharm.setsunan.ac.jp
}

CCMT $[15,17]$.

The relationships among surgical margin and prognosis or recurrence have been reported by several researchers. In grade II tumors, a complete surgical margin accurately predicted a good prognosis $[21,27]$. The frequency of recurrence in the complete surgical excision cases was significantly lower than in incomplete surgical excision during 24 months following surgery [13]. In contrast, the percentage of recurrence of incomplete excision cases of grade II mast cell tumors was only $50 \%$ [13], so about $50 \%$ of incomplete excision cases did not show recurrence. From these facts, many veterinary practitioners would like other more accurate prognostic factors in incomplete excision cases.

Among the many kinetic parameters, ki-67 protein is present at all active phases of the cell cycle $\left(G_{1}, S, G_{2}\right.$, and mitosis), but is absent from resting cells $\left(\mathrm{G}_{0}\right)$. From these characteristics, ki-67 protein is an excellent marker for determining proliferating cells, in human and animal neoplasms. The ki-67 monoclonal antibody (MIB-1) can be detected on formalin-fixed paraffin-embedded section immunohistochemistry. In canine cutaneous mast cell tumors, ki-67 protein has a prognostic value, and has shown a significant correlation with clinical outcome and histological grading [1].

Cyclin D1 is positive regulator of $\mathrm{G}_{1}$ phase progression in the cell cycle, which is achieved in a cdk-dependent manner. The function of cyclin D1 activates cdk4 to catalyze initial phosphorylation of $\mathrm{Rb}$, and releases E2F transcription factors from $\mathrm{pRb}-\mathrm{E} 2 \mathrm{~F}$ complexes. Cyclin $\mathrm{D} 1$ protein is overex- 
pressed in human breast cancer, but it is unlikely to be a strong prognostic marker [6]. In dog, cyclin D1 protein is also overexpressed in mammary carcinoma, squamous cell carcinoma, basal cell carcinoma, plasmacytoma, and multiple myeloma $[5,14,22]$. However, expression status and prognostic role have not been studied in canine cutaneous mast cell tumors.

The aims of this study are, first, to examine the recurrence and prognosis for grade II canine cutaneous mast cell tumors following complete or incomplete surgical excision, and second, to evaluate the prognostic value for ki-67 and cyclinD1 in incomplete surgical excision cases of grade II tumors.

\section{MATERIALS AND METHODS}

Tumors: Surgically resected biopsy specimens of cutaneous mast cell tumors from 306 dogs were sent to Setsunan University for histopathological examination from 1991 to 1998. Of the total of 306 cases stored in the archive during this time period, 48 were solitary cutaneous mast cell tumors with a Grade II histopathological classification using Patnaik's system and stage I using WHO clinical staging system. Two pathologists (K. Ozaki and I. Narama) were involved in grading the mast cell tumors. Of the 48 dogs with a single tumor mass, 24 were Mongrels, 6 were Sheh tzu, 4 were Shetland sheepdog, 4 were Shiba, 3 were Maltese, 3 were Pug, 2 were Toy poodle and 1 each was a Setter and Chihuahua. Their average age was $8.9 \pm 3.1$ years (range 3-15 years, median 9 years). Twenty-three were intact males, one was a neutered male, 10 were intact females, and 14 were neutered females. All tumor masses were located in the skin of the fore and hind limb (19/48), trunk (15/48), head and neck (7/48), tail (2/48) and inguinal and perineal $(5 / 48)$ area. The median tumor size was approximately $2 \mathrm{~cm}$ (ranges, 0.5 to $6 \mathrm{~cm}$ ). Dogs that received chemotherapy or radiation therapy, or for which no postoperative follow-up over 360 days was available in survival cases, were excluded from this study.

A complete history and follow-up information for each case were obtained from the referring veterinarians, including age, sex, breed, weight, number of masses, location of mass, tumor size, time before excision, medication at the time of surgery, clinical tests for diagnosis, recurrence, tumor margins, metastasis, survival time, and cause of death. For the purpose of the study, recurrence was defined as clinical reappearance of a mass at the initial tumor site. Metastasis was defined as the development of an additional mass at a site distant from where the original mass was resected.

Histology and immunohistochemistry: Specimens were fixed in 10\% phosphate-buffered or neutral formalin $(\mathrm{pH}$ 7.4), sectioned in a cross and vertical-sectional manner, and all sections were used. All samples were dehydrated in a graded series of ethanol, and embedded in paraffin, then 4$\mu \mathrm{m}$-thick sections were stained with hematoxylin and eosin. Tumor grading was classified according to Patnaik. Histo- pathological complete surgical excisions were defined as the absence of tumor cells in the surgical margins.

For immunohistochemistry, the primary antibodies used were anti-human cyclin D1 monoclonal antibody (1:200, DCS-6, Lab Vision, Fremont, CA, U.S.A.), and anti-human Ki-67 monoclonal antibody (MIB-1, 1:50, DAKO, Kyoto, Japan); for each, an appropriate normal canine tissue sample was used as a positive control. Tissue sections for assay of cyclin D1 were immersed in $0.01 \mathrm{M}$ citrate buffer ( $\mathrm{pH}$ 6.0) and microwaved at $600 \mathrm{~W}$ for $20 \mathrm{~min}$ to retrieve antigens; and tissue sections for assay of MIB-1 were immersed in $0.01 \mathrm{M}$ citrate buffer $(\mathrm{pH} 6.0)$ and autoclaved at $120^{\circ} \mathrm{C}$ for 15 min to retrieve antigens. All slides were rinsed with 0.05 $\mathrm{M}$ Tris buffer saline (TBS, pH 7.6), 0.01\% Tween 20, treated with $1 \%$ hydrogen peroxide and again rinsed with TBS plus Tween 20. Slides were incubated in bovine serum for $5 \mathrm{~min}$ and with primary antibodies overnight at $4^{\circ} \mathrm{C}$. The slides were subsequently rinsed with TBS plus Tween 20, treated for $30 \mathrm{~min}$ at room temperature with N-Histofine MAX PO (M) (Nichirei, Tokyo, Japan), rinsed with TBS plus Tween 20 , incubated in diaminobenzidine solution containing $0.01 \%$ hydrogen peroxide for the peroxidase coloring reaction, and counterstained with Mayer's hematoxylin. To evaluate cell proliferation activity using ki-67 staining (ki-67 index), we counted the number of strongly positive cells among more than 500 cells in randomized 3 to 10 high power fields $(\times 400)$. For cyclin D1, positive staining of over $10 \%$ of tumor cells among more than 500 cells was judged as positive in randomized 3 to 10 high power fields $(\times 400)$. These measurements were obtained with image processing and analysis software (Ultimage pro Ver. 2.6.1., Graftek, France).

Statistical analysis: Case information was compiled using Stat Mate III software (Atms, Tokyo, Japan). For statistical analysis of categorical variables that had two groups, a Pearson's chi-square test was used. For categorical variables where cell size was $<10$, a Fisher's exact test was used. For each variable with prognostic value, the survival of dogs was plotted by the Kaplan-Meier method. Survival for each subgroup was compared by the logrank and Wilcoxon method. A value of $\mathrm{P}<0.05$ was considered statistically significant.

\section{RESULTS}

The age, sex, tumor location, follow-up and recurrence of dogs with grade II tumor are summarized in Table 1.

Eleven dogs had complete surgical excision, and 37 dogs had incomplete surgical excision. In the complete surgical excision group, 3 dogs (27.3\%) had metastasis and no recurrence in the same skin region, and 8 dogs $(72.7 \%)$ showed no recurrence or metastasis. Three dogs with metastasis died of tumor-unrelated causes. In incomplete surgical excision group, 2 dogs $(5.4 \%)$ showed a recurred mass in the same skin region, $10 \operatorname{dogs}(27.0 \%)$ in a different skin region, 3 dogs $(8.1 \%)$ had metastatic proliferation of tumor cells in the regional lymph node without recurrence, and 22 dogs 
Table 1. Age, sex, tumor location, follow-up and recurrence date of dogs with grade II cutaneous mast cell tumor

\begin{tabular}{|c|c|c|c|}
\hline & & $\begin{array}{l}\text { Complete excision group } \\
\qquad(\mathrm{n}=11)\end{array}$ & $\begin{array}{l}\text { Incomplete excision group } \\
\qquad(\mathrm{n}=37)\end{array}$ \\
\hline \multicolumn{2}{|l|}{ Median Age (yrs) } & 7.9 & 9.2 \\
\hline \multicolumn{2}{|l|}{ Age range } & $3-13$ & $3-15$ \\
\hline \multirow[t]{4}{*}{ Gender } & Neutered female & & 59 \\
\hline & Intact female & 3 & 7 \\
\hline & Neutered male & 0 & 1 \\
\hline & Intact male & 3 & 20 \\
\hline \multirow[t]{5}{*}{ Tumor site } & Head and Neck & & 07 \\
\hline & Trunk & 4 & 11 \\
\hline & Limb & 5 & 14 \\
\hline & Tail & 2 & 0 \\
\hline & Inguinal and perineal & 0 & 5 \\
\hline \multicolumn{2}{|c|}{ Number of dogs with recurrence in same site( \%) } & $0(0 \%)$ & $2(5.4 \%)$ \\
\hline \multicolumn{2}{|c|}{ Number of dogs with metastasis (\%) } & $3(27.3 \%)$ & $13(35.1 \%)$ \\
\hline \multicolumn{2}{|c|}{ Number followed to death (\%) } & $5(45.5 \%)$ & $20(54.1 \%)$ \\
\hline \multicolumn{2}{|c|}{ Number died $<30$ months postoperatively (\%) } & $0(0 \%)$ & $13(35.1 \%)$ \\
\hline \multicolumn{2}{|c|}{ Number died of mast cell tumor-related (\%) } & $0(0 \%)$ & $8(21.7 \%)$ \\
\hline
\end{tabular}

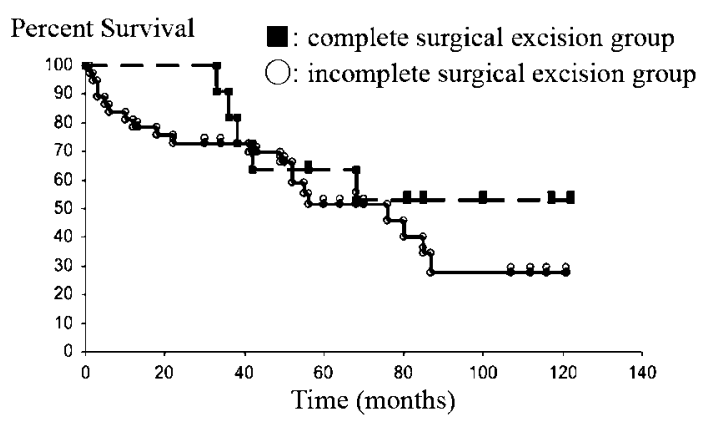

Fig. 1. Kaplan-Meier survival analysis for survival of dogs with complete and incomplete surgical excision of grade II cutaneous mast cell tumor. $\mathbf{\square}=$ complete surgical excision group, $\bigcirc=$ incomplete surgical excision group. $\mathrm{p}=0.324$ (log-rank test).

$(59.5 \%)$ showed no recurrence or metastasis. Out of 15 dogs $(40.5 \%, 15 / 37)$ showing recurrence and/or metastasis, 8 dogs $(53.3 \%, 8 / 15)$ died of mast cell tumor and 7 dogs of tumor-unrelated (3) or unknown causes (4). However, there was no significant difference in the mortality rate due to mast cell tumor between the complete and incomplete surgical excision group $(\mathrm{p}=0.0784)$.

Median follow-up time for all 48 dogs was 1080 days (range, 30 to 3540 days). The proportion of survivors in the complete surgical excision group within 30 months was significantly higher than in the incomplete surgical excision group $(\mathrm{p}=0.0296)$ (Fig. 1). Within 30 months postoperatively, 13 dogs $(35.1 \%, 13 / 37)$ in the incomplete surgical excision groups were dead. Ten dogs $(76.9 \%, 10 / 13)$ of the dogs that did had a recurrence and/or metastasis in the skin or a metastasis to the regional lymph node, and $7 \mathrm{dogs}$ $(53.8 \%, 7 / 13)$ died from the tumor-related cause. However, during the entire investigation, the difference in the proportion of survivors between the complete and incomplete surgical excision groups was not significant $(\mathrm{p}=0.324)$ (Fig. 1).

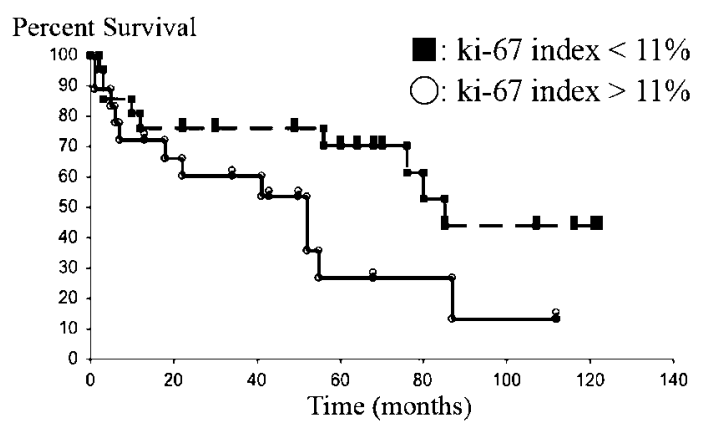

Fig. 2. Kaplan-Meier survival analysis for survival of dogs based on ki-67 index in incomplete surgical excision group of grade II cutaneous mast cell tumor. Breaking point was at the median $(11 \%)$. $=\mathrm{ki}-67$ index $<11 \%, \bigcirc=\mathrm{ki}-67$ index $>11 \%$. p $=0.0485(\log -$ rank test).

The average ki-67 index in the incomplete surgical excision group was $11.6 \%$. When dogs were grouped on the breaking point based on the median (11\%), a significantly higher proportion of survivors were shown in dogs with a ki67 index lower than $11 \%(\mathrm{p}=0.0485)$ (Fig. 2). There was no significant difference in the ki-67 index between recurrence and/or metastasis $(11.3+/-7.1 \%)$, and no-recurrence and metastasis $(11.8+/-8.4 \%)$ in the incomplete surgical excision group.

Immunohistochemically, Cyclin D1 was localized within the nuclei of tumor cells. Positivity was $0 \%$ to $40 \%$, and positive intensity varied from weak to strong. Only 5 cases were positive (positivity was $>10 \%$ ) in the incomplete surgical excision group, but 4 cases had a recurrence and/or metastasis in the skin and one case metastasized to the lymph node. These 4 dogs were died within 24 months; one dog died of mast cell tumor and 3 dogs of unknown causes. However, there was no significant difference in survival rate $(\mathrm{p}=0.1087)$ (Fig. 3). 


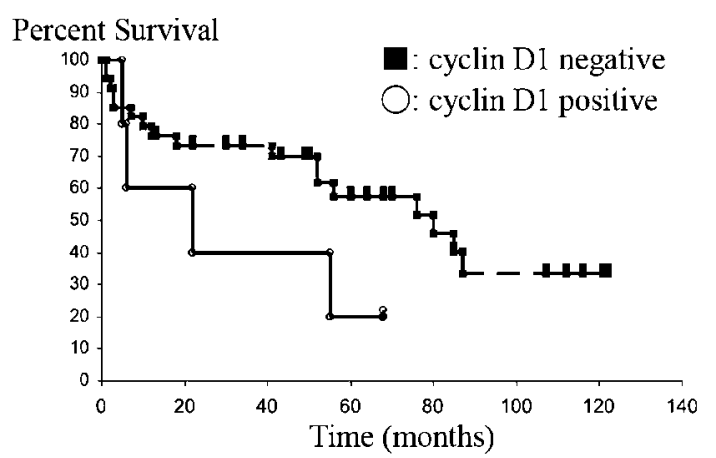

Fig. 3. Kaplan-Meier survival analysis for survival of dogs based on cyclin D1-positive in incomplete surgical excision group of grade II cutaneous mast cell tumor. $\square=$ cyclin D1 negative, $\mathrm{O}=$ cyclin $\mathrm{D} 1$ positive. $\mathrm{p}=0.1087$ (log-rank test).

\section{DISCUSSION}

This study showed that dogs with an incomplete surgical excision of grade II mast cell tumor were more liable to have a recurrence and metastasis compared to those with a complete surgical excision. Tumor recurrence developed in a small number of dogs with completely excised, grade II, cutaneous mast cell tumors [21,27], suggesting that a complete excision can reduce recurrence. In a prior study, the frequency of recurrence in complete surgical excision within 24 months postoperatively was significantly lower than in incomplete surgical excision [13]. These previous findings corresponded with our data. Local tumor recurrence was only seen in $2(5.4 \%)$ dogs in the incomplete surgical excision group in our study. The fact is that, in accordance with findings of three previous reports, the local recurrence rate of grade II mast cell tumors was low [13, 15, 20]. The reasons for this low local recurrence rate for incomplete margin are still not known. It is very interesting that an incomplete margin may lead to metastasis, even when related to local tumor recurrence.

The postoperative survival rate within 30 months in the incomplete surgical excision group was significantly lower compared to those in the complete surgical excision group. Tumor-related deaths in the incomplete surgical excision group within 30 months accounted for 7 of the 13 death cases. Because tumor-related death tends to occur within 30 months postoperatively, it may show a significant difference. However, in the whole study period, there was no significant difference between incomplete and complete surgical excision, because there was only tumor-related death after 30 months postoperatively, and other deaths were not tumor-related regardless of the type of surgical excision.

In the present study, $44.4 \%$ of the recurrent and/or metastasized cases led to tumor-related deaths, suggesting that recurrence and metastasis may be associated with a poor prognosis. In another study, local recurrence was a negative prognostic factor for overall survival in incomplete surgical excision of grade II tumor [20]. However, only $20 \%$ of recurrences reportedly result in poor prognosis and death in mast cell tumors [13]. One reason for the striking discrepancy was that the reports of Michels et al. included various histopathological grade tumors, whereas those of Seguin et $a l$. and our study included only grade II tumors [13, 20].

When considering only the survival rate aside from causes of death, we confirmed the ki-67 index was indeed a prognostic factor for the incomplete surgical excision group with grade II mast cell tumor, given that the survival rate was low when ki-67 protein positivity was high. The ki-67 index of canine mast cell tumor was significantly correlated with histopathological grade and clinical outcome (dead vs alive), and had prognostic potential [1]. The findings in a previous report were corresponded with our data [1]. There was no difference whatsoever in the ki-67 positivity in our study, when the recurrence and metastasis, and non-recurrence and metastasis cases in the incomplete surgical excision group were compared. As in the results of other studies, it was clear from the present investigation that the ki-67 index alone was not a prognostic factor for local recurrence in incomplete surgical excision of grade II tumor [20]. Thus, it was clear that independent use of the ki-67 index did not predict tumor recurrence in grade II mast cell tumors. However, the combination of ki-67 and PCNA scores was prognostic for local recurrence in the group with incomplete surgical excision of grade II tumor [20]. The combination of kinetic factors is needed to predict recurrence.

The percentage of positive cells of cyclin D1 was very low in grade II mast cell tumors, and only 5 cases were judged to be positive. Cyclin D1 expression was very low and moderate in canine mammary carcinoma, moderate in canine multiple myelomas and very low in canine squamous cell carcinoma and plasmacytoma of skin [5, 14, 22]. But there are no reports of canine cutaneous mast cell tumors. In our study, 4 out of 5 positive cases had a poor outcome with high recurrence rate. However, cyclin D1 positivity might not be useful as a prognostic factor because of the low sensitivity.

In grade-II canine cutaneous mast cell tumors, incomplete excision induces a relatively high rate of metastasis and poor prognosis. Ki-67 positivity is a reliable marker for the estimation of overall survival in incomplete margin cases of grade-II canine cutaneous mast cell tumors, but not for recurrence and metastasis. Cyclin D1 positivity may not have any prognostic implication.

ACKNOWLEDGMENT. We thank Dr. Tetsuro Matsuura, Setsunan University, for his assistance in the statistical analysis.

\section{REFERENCES}

1. Abadie, J.J., Amardeilh, M.A. and Delverdier, M.E. 1999. Immunohistochemical detection of proliferating cell nuclear antigen and Ki-67 in mast cell tumors from dogs. J. Am. Vet. Med. Assoc. 215: 1629-1634.

2. Ayl, R.D., Couto, C.G., Hammer, A.S., Weisbrode, S., Ericson, 
J.G. and Mathes, L. 1992. Correlation of DNA ploidy to tumor histologic grade, clinical variables, and survival in dogs with mast cell tumors. Vet. Pathol. 29: 386-390.

3. Bostock, D.E. 1973. The prognosis following surgical removal of mastocytomas in dogs. J. Small Anim. Pract. 14: 27-40.

4. Cahalane, A.K., Payne, S., Barber, L.G., Duda, L.E., Henry, C.J., Mauldin, G.E., Frimberger, A.E., Cotter, S.M. and Moore, A.S. 2004. Prognostic factors for survival of dogs with inguinal and perineal mast cell tumors treated surgically with or without adjunctive treatment: 68 cases (1994-2002). J. Am. Vet. Med. Assoc. 225: 401-408.

5. Cangul, I.T., Wijnen, M., Van Garderen, E. and van den Ingh, T.S. 2002. Clinico-pathological aspects of canine cutaneous and mucocutaneous plasmacytomas. J. Vet. Med. A Physiol. Pathol. Clin. Med. 49: 307-312.

6. Colozza, M., Azambuja, E., Cardoso, F., Sotiriou, C., Larsimont, D. and Piccart, M.J. 2005. Proliferative markers as prognostic and predictive tools in early breast cancer: where are we now? Ann. Oncol. 16: 1723-1739.

7. Ginn, P.E., Fox, L.E., Brower, J.C., Gaskin, A., Kurzman, I.D. and Kubilis, P.S. 2000. Immunohistochemical detection of p53 tumor-suppressor protein is a poor indicator of prognosis for canine cutaneous mast cell tumors. Vet. Pathol. 37: 33-39.

8. Jaffe, M.H., Hosgood, G., Taylor, H.W., Kerwin, S.C., Hedlund, C.S., Lopez, M.K., Davidson, J.R., Miller, D.M. and Paranjpe, M. 2000. Immunohistochemical and clinical evaluation of p53 in canine cutaneous mast cell tumors. Vet. Pathol. 37: $40-46$.

9. Kiupel, M., Webster, J.D., Kaneene, J.B., Miller, R. and Yuzbasiyan-Gurkan, V. 2004. The use of KIT and tryptase expression patterns as prognostic tools for canine cutaneous mast cell tumors. Vet. Pathol. 41: 371-377.

10. Kiupel, M., Webster, J.D., Miller, R.A. and Kaneene, J.B. 2005. Impact of tumour depth, tumour location and multiple synchronous masses on the prognosis of canine cutaneous mast cell tumours. J. Vet. Med. A Physiol. Pathol. Clin. Med. 52: 280-286.

11. Kravis, L.D., Vail, D.M., Kisseberth, W.C., Ogilvie, G.K. and Volk, L.M. 1996. Frequency of argyrophilic nucleolar organizer regions in fine-needle aspirates and biopsy specimens from mast cell tumors in dogs. J. Am. Vet. Med. Assoc. 209: $1418-1420$.

12. Macy, D.W. 1985. Canine mast cell tumors. Vet. Clin. North Am. (Small Anim. Pract.) 15: 783-803.

13. Michels, G.M., Knapp, D.W., DeNicola, D.B., Glickman, N. and Bonney, P. 2002. Prognosis following surgical excision of canine cutaneous mast cell tumors with histopathologically tumor-free versus nontumor-free margins: a retrospective study of 31 cases. J. Am. Anim. Hosp. Assoc. 38: 458-466.

14. Murakami, Y., Tateyama, S., Rungsipipat, A., Uchida, K. and Yamaguchi, R. 2000. Immunohistochemical analysis of cyclin
A, cyclin D1 and P53 in mammary tumors, squamous cell carcinomas and basal cell tumors of dogs and cats. J. Vet. Med. Sci. 62: 743-750.

15. Murphy, S., Sparkes, A.H., Smith, K.C., Blunden, A.S. and Brearley, M.J. 2004. Relationships between the histological grade of cutaneous mast cell tumours in dogs, their survival and the efficacy of surgical resection. Vet. Rec. 154: 743-746.

16. O'Keefe, D.A. 1990. Canine mast cell tumors. Vet. Clin. North Am. (Small Anim. Pract.) 20: 1105-1115.

17. Patnaik, A.K., Ehler, W.J. and MacEwen, E.G. 1984. Canine cutaneous mast cell tumor: morphologic grading and survival time in 83 dogs. Vet. Pathol. 21: 469-474.

18. Preziosi, R., Sarli, G. and Paltrinieri, M. 2004. Prognostic value of intratumoral vessel density in cutaneous mast cell tumors of the dog. J. Comp. Pathol. 130: 143-151.

19. Sakai, H., Noda, A., Shirai, N., Iidaka, T., Yanai, T. and Masegi, T. 2002. Proliferative activity of canine mast cell tumours evaluated by bromodeoxyuridine incorporation and Ki-67 expression. J. Comp. Pathol. 127: 233-238.

20. Seguin, B., Besancon, M.F., McCallan, J.L., Dewe, L.L., Tenwolde, M.C., Wong, E.K. and Kent, M.S. 2006. Recurrence rate, clinical outcome, and cellular proliferation indices as prognostic indicators after incomplete surgical excision of cutaneous grade II mast cell tumors: 28 dogs (1994-2002). $J$. Vet. Intern. Med. 20: 933-940.

21. Seguin, B., Leibman, N.F., Bregazzi, V.S., Ogilvie, G.K., Powers, B.E., Dernell, W.S., Fettman, M.J. and Withrow, S.J. 2001. Clinical outcome of dogs with grade-II mast cell tumors treated with surgery alone: 55 cases (1996-1999). J. Am. Vet. Med. Assoc. 218: 1120-1123.

22. Sfacteria, A., Bertani, C., Costantino, G., Del Bue, M., Paiardini, M., Cervasi, B., Piedimonte, A. and De Vico, G. 2003. Cyclin D1 expression in pre-cancerous and cancerous lesions of the canine mammary gland. J. Comp. Pathol. 128: 245-251.

23. Simoes, J.P.C., Schoning, P. and Butine, M. 1994. Prognosis of canine mast cell tumors: a comparison of three methods. Vet. Pathol. 31: 637-647.

24. Strefezzi Rde, F., Xavier, J.G. and Catao-Dias, J.L. 2003. Morphometry of canine cutaneous mast cell tumors. Vet. Pathol. 40: $268-275$.

25. Webster, J.D., Kiupel, M. and Yuzbasiyan-Gurkan, V. 2006. Evaluation of the kinase domain of c-KIT in canine cutaneous mast cell tumors. BMC cancer [electronic resource] 6: 85 .

26. Webster, J.D., Yuzbasiyan-Gurkan, V., Kaneene, J.B., Miller, R., Resau, J.H. and Kiupel, M. 2006. The role of c-KIT in tumorigenesis: evaluation in canine cutaneous mast cell tumors. Neoplasia (New York, N.Y) 8: 104-111.

27. Weisse, C., Shofer, F.S. and Sorenmo, K. 2002. Recurrence rates and sites for grade II canine cutaneous mast cell tumors following complete surgical excision. J. Am. Anim. Hosp. Assoc. 38: 71-73. 